\title{
ANALISIS RENCANA PEMBELAJARAN GURU MATEMATIKA DI MADRASAH ALIYAH BILINGUAL BATU
}

\author{
Baiduri' $^{1)}$, Hendarto Cahyono ${ }^{2}$, Akhsanul In’am²), Siti Rukayah' ${ }^{4)}$ \\ FKIP Universitas Muhammadiyah Malang,2,3) \\ Ma Bilingual Batu ${ }^{4)}$ \\ Email $^{1)}$ : baiduriumm@gmail.com \\ Email ${ }^{2}$ : hendarto@umm.ac.id \\ Email3):akhsanul@umm.ac.id \\ Email ${ }^{4)}$ : rukayah77siti@gmail.com
}

\begin{abstract}
ABSTRAK
Tujuan dari makalah ini adalah menganalisis rencana pembelajaran (RPP) guru matematika di Madrasah Aliyah Bilingual Batu, khusunya pada kegiatan inti proses pembelajaran yang akan dilakukan. Jenis penelitian deskriptif dengan pendekatan kualitatif digunakan untuk maksud tersebut. Seorang guru matematika kelas X dijadikan subjek. Data dikumpulkan melalui dokumentasi dan focus group discussion serta dianalisis secara deskriptif. Hasil analisis memperlihatkan bahwa komponen RPP yang disusun oleh guru sesuai dengan permendikbud Nomor 81A tahun 2013. Pada komponen inti kegiatan pembelajaran guru sudah menggunakan berbagai model, metode dan pendekatan sebagai upaya meningkatkan keterlibatan peran aktif peserta didik dalam proses pembelajaran yang akan dilaksanakan.
\end{abstract}

Kata Kunci: Rencana pembelajaran, kegiatan pembelajaran, matematika.

\begin{abstract}
The purpose of this paper is to analyze the learning plan ( RPP ) of Mathematics teacher at Madrasah Aliyah Bilingual Batu, especially in the core activities of the learning process to be performed. Descriptive research with a qualitative approach is applied for this purpose. One Mathematics teacher in grade $\mathrm{X}$ were used as the subject. The data were collected through documentation and focus group discussion and analyzed descriptively. The results showed that the RPP component prepared by the teacher is in accordance with Permendikbud No. 81A 2013. At the core component of the learning activities, the teacher is already using a variety of models, methods and approaches as an effort to increase the involvement of the active role of learners in the performed learning process.
\end{abstract}

Keywords: Lesson plans, learning activities, Mathematics

\section{PENDAHULUAN}

Guru adalah pendidik profesional dengan tugas utama mendidik, mengajar, membimbing, mengarahkan, melatih, menilai, dan mengevaluasi peserta didik pada pendidikan anak usia dini jalur pendidikan formal, pendidikan dasar, dan pendidikan menengah (UURI No. 14 psl
1:1, 2005). Dilihat dari tugasnya, guru mempunyai pekerjaan yang tidak ringan dalam mengantarkan siswanya menjadi insan yang berhasil. Guru merancang, mengorganisir proses pembelajaran dan melakukan evaluasi untuk mengubah penampilan siswanya secara bermakna atau tidak. Oleh karenanya peran guru sangat 
penting dalam menentukan keberhasilan siswanya. “ ... teachers are key to students' opportunities to learn mathematics.” (Even dan Ball, 2009). Apa yang dilakukan oleh peserta didik dalam proses pembelajaran merupakan cermin bagaimana metode atau strategi yang digunakan oleh guru.

Guru merupakan pemegang peran utama dalam proses belajar mengajar. Proses belajar mengajar adalah proses yang mengandung serangkaian perbuatan guru dan siswa atau dasar hubungan timbal balik yang berlangsung dalam situasi edukatif untuk mencapai tujuan tertentu. Seorang guru memiliki banyak tugas, baik yang terikat oleh dinas maupun diluar dinas. Sabri (2007) menyatakan bahwa tugas guru dapat dikelompokan berupa tugas dalam bidang profesi, tugas kemanusiaan, dan tugas dalam bidang kemasyarakatan. Pelaksanaan tugas-tugas tersebut menuntut guru memili berbagai kemampuan dan wewenang atau kompetensi.

Kompetensi guru adalah seperangkat penguasaan, kemampuan yang harus ada dalam diri guru agar dapat mewujudkan kinerjanya secara tepat dan efektif (Kunandar, 2007). Jadi kompetensi guru dapat dimaknai sebagai kebulatan pengetahuan, keterampilan dan sikap yang berujud tindakan cerdas dan penuh tanggung-jawab dalam melaksnakan tugas sebagai agen pembelajaran. Berdasarkan UU No. 14 Tahun 2005 telah dinyatakan bahwa kompetensi seorang guru meliputi kompetensi kepribadian, kompetensi pedagogik, kompetensi profesional, dan kompetensi sosial (Usman, 2011).

Kompetensi profesional merupakan kemampuan guru dalam menguasai materi pembelajaran secara luas dan mendalam, yang memungkinkan peserta didik memenuhi standar kompetensi yang ditetapkan standar nasional pendidikan. Kompetensi paedagogik merupakan kemampuan guru dalam mengelola pembelajaran peserta didik yang sekurangkurangnya meliputi : pemahaman wawasan landasan kependidikan, pemahaman terhadap peserta didik, pemahaman kurikulum atau silabus, perencanaan pembel-ajaran, pelaksanaan pembelajaran yang mendidik dan dialogis, evaluasi hasil belajar, pengembangan peserta didik untuk mengaktualisasikan berbagai potensi yang dimiliki. Kedua kompetensi ini diharapkan dapat membantu guru dalam membimbing siswa untuk berperan aktif dalam proses pembelajaran di kelas.

Berdasarkan hasil diskusi terbatas dengan guru matematika di Madrasah Aliyah Bilingual Batu pembelajaran matematika, guru masih berperan aktif sedangkan siswanya pasif dan pada saat guru menyampaikan materi, siswa yang berada dibelakang melakukan kegiatan sendiri, berbicara dengan teman dan tidurtiduran. Sementara itu di sekolah tersebut sudah menerapkan kurikulum 2013, dimana pendekatan pembelajaran menggunakan pendekatan saintifik yang menuntut peran aktif siswa dalam proses pembelajaran di kelas. Berdasarkan kenyataan ini, apakah rencana pelaksanaan pembelajaran (RPP) yang dibuat oleh guru matematika telah melibatkan peran aktif siswa?

\section{METODE}

Penelitian ini merupakan penelitian deskriptif dengan pendekatan kualitatif karena bertujuan menganalisis perangkat rencana pelaksanaan pembelajaran yang disusun oleh guru matematika MA Bilingua Batu apa adanya, tanpa manipulasi variabel atau pengujian statistik. Subjeknya adalah guru matematika kelas X MA Bilingual 
Batu. Data dikumpulkan melalui dokumentasi dan FGD (focus group discussion) dan dianalisis secara dekriptif. Dokumentasi digunakan untuk melihat RPP yang sudah disusun oleh guru matematika. Sedangkan FGD dilakukan dalam upaya menentukan materi yang akan dirancang serta kesesuaian antara RPP yang sudah disusun dengan teori yang digunakan.

\section{HASIL DAN PEMBAHASAN}

\section{1) Materi yang disusun RPP-nya}

Berdasarkan hasil FGD, materi yang akan dijadikan penelitian ada 4 (empat), yaitu: 1) sistem persamaan dan pertidaksamaan linier dua dan tiga varibel, 2) matriks, 3) relasi dan fungsi dan 4) barisan dan deret. Akan tetapi karena banyaknya agenda kegiatan sekolah berkaitan dengan pelaksanaan semester ganjil, maka materi yang ke-4, barisan dan deret tidak diikutsertakan..

\section{2) Hasil FGD tentang penyusunan RPP}

Secara umum RPP yang disusun oleh guru berupaya untuk melibatkan peran aktif peserta didik dalam proses pembelajaran. Komponen RPP sudah jelas dan sesuai dengan Permendikbud Nomor 81A tahun 2013. Kompetensi inti (KI), kompetensi dasar (KD), dan indikator sudah sesuai dengan yang ada pada kurikulum 2013. FGD difokuskan pada kegiatan inti pada RPP yang telah disusun oleh guru.

\subsection{Sistem Persamaan dan Pertidaksamaan Linier Dua dan Tiga Varibel}

Pada RPP yang telah disusun oleh guru kegiatan inti terdiri dari 5 fase; Fase 1: Orientasi siswa pada masalah (mengamati), Fase 2: Mengorganisasikan siswa belajar (menanya), Fase 3: Membimbing penyelidikan individu dan kelompok (mencoba), Fase 4: Mengembangkan dan menyajikan hasil karya (menalar), dan Fase 5: Menganalisa dan mengevaluasi proses pemecahan masalah (mengkomunikasikan). Meskipun fase pembelajarannya sudah merujuk pada problem-based learning / PBL, akan tetapi aktivitas antara fase masih terlihat saling lepas belum terpadu serta belum sesuai dengan model pembelajaran yang dipilih, yaitu pembelajaran berbasis masalah. Berdasarkan model pembelajaran berbasis masalah dan pendekatan saintifik, maka didiskusikan aktivitas apa yang sesuai dengan keduanya. Pembelajaran berbasis masalah (problem-based learning / PBL) adalah konsep pembelajaran yang membantu guru menciptakan lingkungan pembelajaran yang dimulai dengan masalah yang penting dan relevan (bersangkut-paut) bagi peserta didik, dan memungkinkan peserta didik memperoleh pengalaman belajar yang lebih realistik (Burg, 2010). Ini berarti hal utama yang harus diperhatikan adalah masalah apa yang diberikan kepada siswa yang sesuai dengan materi dan berkaitan dengan aktivitas mereka.

Hasil diskusi menyepakati bahwa aktivitas pertama yang akan dilakukan adalah memberikan maslah otentik (sesuai dengan pengalaman siswa) yang akan diselesaikan berkaitan dengan materi sistem persamaan linier dua variabel. Berdasarkan masalah yang diberikan tersebut siswa melakukan berbagai aktivitas; mengamati, bertanya, mencoba, bernalar dan berkomunikasi untuk menyelesaikan masalah yang diberikan tersebut.

Ketika siswa berusaha menyelesaikan masalah yang diberikan guru dapat memberikan scaffolding jika diperlukan. Selain itu siswa secara aktif 
mengkonstruksikan tentang konsep sistem persamaan linier dua variabel serta prosedur untuk menyelesaikannya. Pada FGD juga dibahas tentang langkah-langkah pembelajaran model PBL. Perbadingan kegiatan inti sebelum dan hasil FGD pada Fase 1 disajikan pada Tabel 1.

Tabel 1. Perbandingan RPP sebelum dan setelah FGD Materi SPL

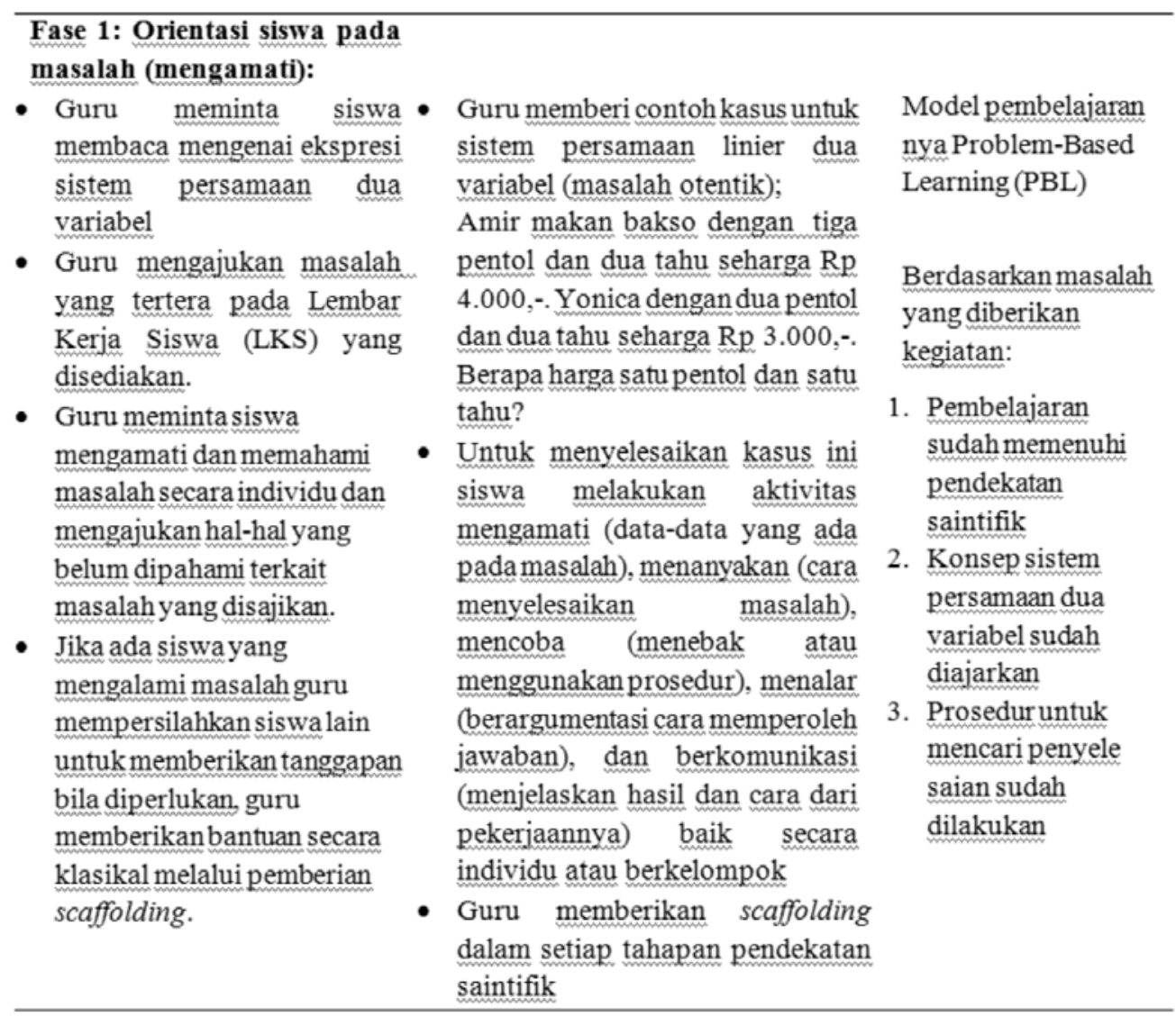

\section{2)Matriks}

Pada materi matriks, RPP yang disusun oleh guru masih menggunakan model $P B L$, pendekatan saintifik serta metode penemuan terbimbing, pemecahan masalah, diskusi kelompok, tanya jawab, dan penugasan. Kegiatan inti pembelajarannya langsung pada pendekatan saintifik. Akan tetapi fasefase PBL belum terlihat secara tegas, dimana fase tersebut digunakan.Pada kegiatan awal (mengamati) guru meminta siswa mengamati posisi tempat duduk di kelas dan bilangan-bilangan yang ada di kalender yang ada di kelas. Hal ini sangat nyata dengan aktivitas siswa sehari-hari di sekolah. Akan tetapi pada kegiatan ini belum terlihat masalah apa yang terkait dengan posisi tempat duduk dan bilangan yang ada di kalender serta apa yang harus dilakukan oleh siswa. Hasil FGD menyarankan masalahnya adalah bagaimana menyusun sebagian posisi tempat duduk atau bilangan-bilangan yang ada dikalender sehingga memiliki makna?. Aktivitas ini dapat individu atau berkelompok. Sehingga dua hal yang semestinya ada dalam aktivitas mengamati, yaitu apa yang diamati dan 
untuk apa mengamati (unsur-unsur masalah). Berdasarkan kedua aktivitas tersebut maka diharapkan aktivitas saintifik yang lainnya secara tidak langsung dilakukan oleh siswa. Tujuan dari pemberian masalah adalah untuk menanamkan konsep matriks, unsurunsur matriks, baris dan kolom, jenisjenis matriks serta operasi aljabar pada matriks.
Sesuai dengan metode yang digunakan kegiatan pembelajaran dapat dilakukan secara berkelompok atau individu serta menggunakan media (lembar kerja siswa) yang dirancang untuk memahami konsep-konsep yang akan dicapai setelah proses pembelajaran. Perbandingan kegiatan inti sebelum dan hasil FGD disajikan pada Tabel 2.

Tabel 2. Perbandingan RPP sebelum dan setelah FGD Materi Matriks

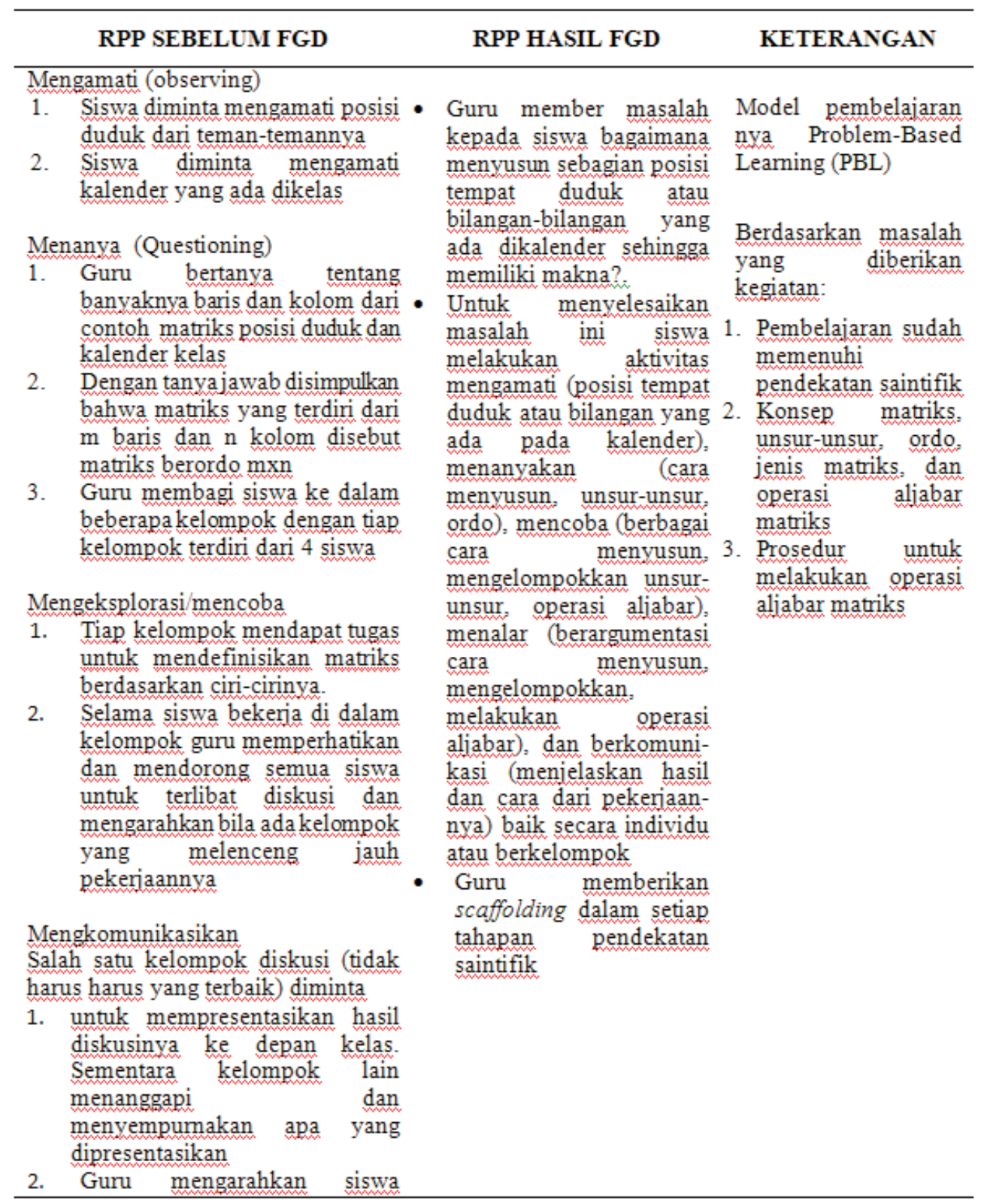

Baiduri, dkk. Analisis Rencana Pembelajaran Guru Matematika di Madrasah Aliyah Bilingual Batu 


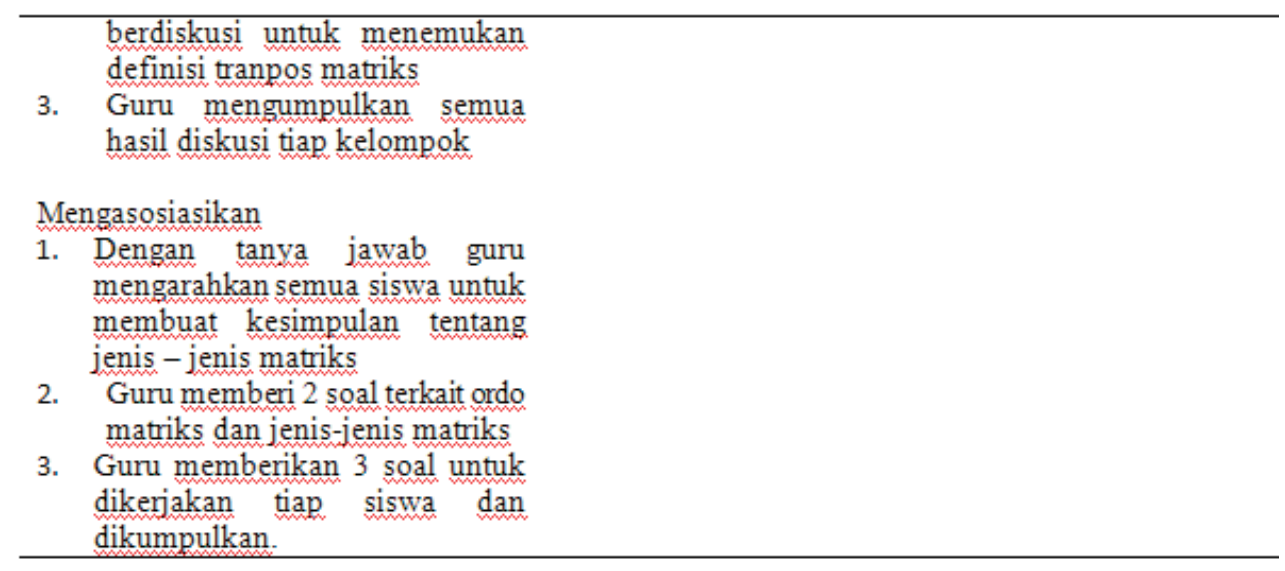

\section{3) Relasi dan Fungsi}

Seperti dua materi sebelumnya, model pembelajaran yang akan digunakan oleh guru ketika menyusun RPP adalah Problem Based Learning dengan pendekatan saintifik. Pada kegiatan inti telah sesuai dengan fase-fase PBL yang terdiri dari 5 fase; Fase 1: Orientasi siswa pada masalah. Fase 2: Mengorganisasikan siswa belajar, Fase 3: Membimbing penyelidikan individu dan kelompok, Fase 4: Mengembangkan dan menyajikan hasil karya, dan Fase 5: Menganalisa dan mengevaluasi proses pemecahan masalah. Pada Fase 1, siswa diberikan masalah yang berkaitan kegitan HUT sebuah Kabupaten dimana beberap siswa sebuah SMA dikirim pada acara tersebut untuk mengikuti perlombaan. Masalahnya siswa diminta untuk memasangkan nama siswa dan jenis pertandingan yang diikutinya dengan diagram panah, pasangan berurut dan diagram kartesius. Pada fase ini juga dijelaskan aktivitas yang berkaitan dengan saintifik. Demikian juga pada empat fase berikutnya. Secara keseluruhan antara model dan pendekatan yang digunakan serta kegiatan inti pembelajaran sudah sesuai. Selain itu hasil FGD menyarankan agar guru menamkan konsep domain dan range dengan menggunakan fungsi secara formal dalam matematika, seperti

\section{SIMPULAN}

Berdasarkan analisis RPP yang disusun oleh guru matematika Madrasah Aliyah Bilingual Batu, pada kegiatan inti pembelajaran sudah disusun berbagai aktivitas untuk melibatkan peran aktif siswa dalam proses pembelajaran. Meskipun demikian perlu adanya kesesuaian antara model, metode dan pendekatan yang dipilih dengan rencana aktivitas yang akan dilakukan pada saat pembelajaran. Untuk itu perlu adanya kolaborasi antara LPTK dan sekolah yang kontinu dalam meningkatan kualitas proses pembelajaran di sekolah, yang dimulai dari penyusunan rencana pelaksanaan pembelajaran.

Pada kesempatan ini, penelitian difokuskan dalam hal rencana pembelajaran yang akan melibatkan peran aktif siswa, yang meliputi teori pembelajaran dan sedikit tentang konsep materinya. Oleh karena itu perlu penelitian lebih lanjut difokuskan pada penyusunan alat evaluasi dan implementasi RPP. 


\section{DAFTAR PUSTAKA}

Anonim, Undang-undang No. 14 Tahun 2005 tentang Guru dan Dosen.

Tahun 2013 Tentang Implementasi Kurikulum

Burg, Oudlaan. 2010. The Interdisciplinary Journal of Problem-based Learning. Spring. Vol. 4, no. 2

Even R.; Ball, D.L. (2009). Setting the stage for the ICMI study on the professional education and development of teachers of mathematics. Pada Even R.; Ball, D.L. (Eds). The Professional Education and Development of Teachers of Mathematics. New York: Springer

Kunandar. 2007. Guru Profesional, Jakarta: Rajagrafindo Persada,

Usman, Uzer. Moh. 2011., Menjadi Guru Profesiona. Bandung: PT Remaja Rosdakarya.

Sabri,Ahmad.2007. Strategi Belajar Mengajar Micro Teaching. Padang:

Quantum Teaching 